\title{
Spatial Equity in Devolved Healthcare: Geospatially Exploring Local Disparities in Maternal Healthcare Uptake After Devolution in Kenya
}

\author{
Samuel Nyangueso, PhD Candidate., \\ Patrick Hayombe, PhD., \\ Fredrick Owino, PhD.,
} Jaramogi Oginga Odinga University of Science and Technology, Kenya

Doi: 10.19044/esj.2018.v14n27p378 URL:http://dx.doi.org/10.19044/esj.2018.v14n27p378

\begin{abstract}
Devolved healthcare in Kenya was to ensure provision of proximate and easily accessible services throughout the Country, thereby improving local uptake as an outcome from patient perspective. Over five years after operationalization of the devolved healthcare, it isn't certain whether or not there have been reducing spatial disparities and/or improving prospects of spatial equity in local utilizations of essential primary healthcare. The paper seeks to explore spatial disparities in maternal healthcare utilization and prospects of realising spatial equity after devolution of healthcare in Kenya. County of Siaya and 30 Wards therein were, respectively, selected as spatially heterogeneous and homogenous multiple cases for the study through retrospective patient-based surveys. The study leveraged on Kenyan webbased health information systems to capture spatial and attribute data on skilled birth attendance and antenatal care before and after devolution by each of the 220 registered health facility the County by Wards. Local utilization ratio, a new innovative indicator, was applied to effectively measure and analyse the spatial disparities in maternal healthcare through ordinary least square spatial regression analysis within spatio-temporal analysis realm using ArcGIS 10.3. Result showed significant positive spatial relationship in maternal service utilizations before and after devolution by Wards $(\mathrm{p}<0.01$, $\mathrm{R}^{2}>90 \%$ ). but stagnating or deteriorating spatial disparities irrespective of either increasing or decreasing uptake of the services. This trend points to lower prospects by devolved healthcare in realizing spatial health equity without improving quality and comprehensiveness of primary health services in Siaya County and related decentralised units in Kenya and beyond.
\end{abstract}

Keywords: Devolved healthcare, Spatial Equity, Local Utilization, Kenya 


\section{Introduction}

Devolution of healthcare was a major health reform in Kenya whose hallmark was transferring administration, service delivery, infrastructure, funding, and staffing functions from national government to 47 county governments effective 2013 (Republic of Kenya, 2010). Devolved healthcare is a product of devolution, which is characterised by transfer of power, resources, functions and responsibilities to sub national units to better address regional and local disparities in developments and service delivery (The World Bank, 2005; Harry, 2006). Similarly, Chapter 11 of the Constitution of Kenya provides that one of the objects of devolution is to promote social and economic development and provision of proximate and easily accessible services throughout the Country. Even though Kenya operationalised devolved healthcare since 2013, there was no certainty on impact or prospect of devolution on health access (KPMG International, 2013), and even utilization. Five years after devolving healthcare in Kenya, it isn't certain whether or not there has been reducing spatial disparities and/or improving prospects of spatial equity in local uptake of essential primary healthcare. Success of devolved healthcare ought to see increasing proportion of primary health needs met locally within 1450 Wards in Kenya, being lowest decentralized service delivery units. Note that two most significant barriers to entry in the Kenyan health system have been the cost of care, and the availability of suitable care within a reasonable distance (Turin, 2010).

Acclaimed progress or impact of devolution in healthcare has been quantitative pronouncements and county progress reports on increasing availability of health resources, but neither on spatial disparities nor equity based on utilization from patient-perspective. Yet key health policy principles in Kenya are "Equity in the distribution of health services and interventions and Peoplecentred approach to health and health interventions" (Republic of Kenya, 2014a). Conceiving spatial equity as desirable level of spatial disparities in healthcare access and utilization within decentralized units, the first hurdles has to be the availability and approach to data collections and analysis. The World Health Organization (WHO) global health indicators on access and utilization (WHO, 2015), being acquired through population-based surveys like demographic and health surveys, are effective spatial equity policy indicators for nations but ineffective intervention indicators at regional and local subnational levels. This is because nations are discernible as self-contained, with limited crossborder health seeking habits, akin to "container view" in accessibility analysis (Talen \& Anselin, 1998; Amer, 2007). This is not true for sub-national units, especially in Kenya where patients have freedom to choose providers, occasioning higher inter-County and inter-Ward health search. Therefore, desirable levels of spatial disparities for devolved healthcare ought to be locally contextualized to measure progress and identify areas for 
improvements after devolution. The paper seeks to explore spatial disparities in maternal healthcare utilization and prospects of realising spatial equity after devolution of healthcare in Kenya through retrospective patient-based surveys.

\section{Devolved Healthcare and Spatial Equity Nexus}

Strategically, devolution is a political and constitutional undertaking attempted at challenging embedded centralized power imbalances that cause and sustain spatial inequity within nations (The World Bank, 2005; Harry, 2006). Devolution of healthcare is a normative concept in theory aimed at attaining health equity, via reducing regional and local spatial disparities in health inputs and outcomes. It occurs when healthcare becomes one of the devolved functions, as in many jurisdictions in developed and developing nations owing to their unique situations. Whereas devolved healthcare is intended at spatial equity and health equity, it has elicited mixed expectations as to whether it can address public health challenges and reduce inequalities (Katikireddi, Smith, Stuckler, \& McKee, 2016). Devolved healthcare involve greater autonomy for locally elected leaders to make key decisions about health service delivery within their jurisdiction.

India has been a classical case where devolved healthcare was argued as a good strategy for spatially equitable access in all regions owing to its uniqueness (WHO, 2008). The country had centralized planning since colonial times, strong caste system in certain regions and uneven approach to decentralizing services which impeded universal access to basic services, including health. In United Kingdom, however, scholars were apprehensive to devolution of healthcare and observed that devolution has inherent possibility of changing ideas, interests and institutions that had potential opportunities and threats to public health arising from political change (Katikireddi, et.al., 2016). It was reasoned that local decision making may result in geographic disparities in provision of health services for people with similar needs, could exacerbate the issue of lack of resources to promote health and wellbeing in poorer parts of the country and interfere with standardised quality of healthcare and service access. Advocates of devolved healthcare nonetheless supported it arguing that it could enhance democratic local decision-making about health care provision, help to integrate services for health and social care, and tailor services to local need.

Philippines, due to its geography, embraced devolution in early 1990s, which devolved basic services including healthcare. However, it negatively affected quality and healthcare coverage in some regions, especially rural and remote areas (Grundy, Healy, Gorgolon, \& Sandig, 2003), which included low staff morale, declined utilization of health facilities, breakdown in management at two levels, maintenance and operational cost between 1992 
and 1997. Remedial interventions had to be taken for improvement within first five years. China experienced decline in spatial health equity following Chinese economic revolution in 1980s' due to degradation of Corporative Medical System (CMS) (Liu, Hsiao, \& Eggleston, 1999). The CMS favoured poor communities in the rural areas, where it provided an infrastructure for healthcare delivery and funding framework based on communal contributions and government subsidy. The abandonment of CMS resulted in significant decline in the quantity of healthcare professionals (by 35.9\%) and functioning clinics from $71 \%$ to $55 \%$ of villages over 14 years (Kanbur \& Zhang, 2005). This was exacerbated by increasing poverty of rural workers, malnutrition, poor hygiene and loss of flight of health professional (Zhao, 2006). Geographically, Western China was worst hit by lower life expectancy (Wang, $\mathrm{Xu}, \& \mathrm{Xu}, 2007)$.

From the foregoing, devolved healthcare is a tool for realizing spatial (health) equity, which is a sub set of health equity. Health equity refers to the study and causes of differences in the quality of health and healthcare amongst different population groups (Venkatapuram, Bell, \& Marmot, 2010; Starfield, 2011). Health inequalities may include presence of disease, health outcomes, or access to health care amongst racial, age, ethnicity, gender, socio-economic status (Goldberg, Hayes, \& Huntley, 2004), all of which have geographical impression. Spatial equity in healthcare is perceived as met when desirable level of spatial (geographic) disparities in access and use of healthcare services is achieved, as per subnational, national and/or global benchmarks. Spatial equity, from the works of geographers David Harvey and Edward W. Soja, links together social justice and space (Harvey, 1992; Soja, 2010). A "just space" space, according to Rawls (2001), is one in which basic requirements of just distribution, equality of basic liberties and the distribution of all other social equalities confers greatest benefit even to the least advantaged. Progress or prospects in achieving spatial equity, from patient perspective, ought to be given by spatial and temporal improvements in health service utilization within service delivery units. Shaikh and Hatcher (2005) reiterated that if health service system is to work, it must start from what users need, such that appropriate policies should be redesigned to address patient needs, based on their health seeking behaviour.

\section{Materials and Methods:}

A retrospective annual patient-based survey and geospatial analysis was undertaken within a devolved unit in a multiple-case design. This was where within one heterogeneous case, there were several homogenous clusters/spatial units involved in the investigations (Yin, 1994; Zaidah, 2007; Creswell J. W., 2013). The design ameliorates perceived lack of robustness linked to single-case design, where only one case and one unit is studied, 
therefore suffers lack of comparative and generalization advantage (Zaidah, 2007). The design allowed for in-depth investigation and inquiry through comparative description and explanation of health seeking and utilization patterns both spatially and qualitatively before and after devolution in the County. Local utilization (LU) and local utilization ratio (LUR), new indicators, were innovatively coined for meaningful and effective measure and analysis. Health service local utilization is perceived as the total number of patients who received a given health service within locally registered health facilities annually, either within a County or Ward. Local utilization potentially increases with increase in populations, which ought to be factored in by applying local utilization ratio (LUR). LUR is the proportions of projected healthcare need (demand) annually met locally, within registered health facilities in a Ward or a County. In other words, local utilization divided by the projected local need. Nationally desirable level of LUR, as per universal health care standards is at least 0.90 (90\%) (STC, 2018). Within Counties and Wards, LUR may not necessary be $90 \%$ owing to higher inter-county and inter-Ward health seeking habits owing arising from patients freedom of choices, preferences or deficiencies in local services. Consequently, spatial equity or inequity has been locally contextualized; to include both global and local spatial equity standards. The study selected two maternal healthcare services, a commonly applied performance assessment for health delivery systems: Skilled birth attendance (SBA) and Antenatal care (ANC). While SBA is necessary to reducing maternal and neonatal mortality, ANC from a skilled provider is important to monitor pregnancy and reduce the risk of morbidity for mother and baby during pregnancy and delivery (Republic of Kenya, 2014b).

\section{Study Area}

County of Siaya in Kenya was representatively selected as the main case, whereas 30 Wards therein were considered as subcases. Of all 47 counties in Kenya, only Nairobi and Mombasa are wholly urbanized, whereas the rest are largely rural just like the selected County. Wards are smaller decentralised units within the counties for county-based representation, legislation, planning, service delivery and resource allocations in Kenya (Republic of Kenya, 2012). There exist a total of 1450 Wards in Kenya, giving average of about 30 per County, making them important local units for downscaling and analysis of health and socio-economic data for local development and addressing disparities in basic service delivery. Maternal healthcare, being a preferred indicator for entire health delivery system and constitutionally emphasised in Kenya (Republic of Kenya, 2010), was selected for analysis. Even in this, Siaya County has one of the highest Maternal Mortality Ratio (MMR) in Kenya, and is among 15 Counties out 
of 47 that accounts for $98.7 \%$ of maternal deaths in Kenya (UNFPA, 2014; 2015). The county's MMR stands at 691 for every 100,000 live births, compared to 495 for every 100,000 live births nationally. The county population as at August 2009 was 842,304, growing at approximately $1.7 \%$ (Siaya CIDP, 2013-2017). Currently the county has 220 registered health facilities comprising 11 hospitals (level 4), 50 health centres (level 3) and 159 dispensaries (level 3). Each of the registered health facilities file and upload patient data into District Health Information System (DHIS 2) as a government policy (Karuri, Waiganjo, Orwa, \& Manya, 2014).

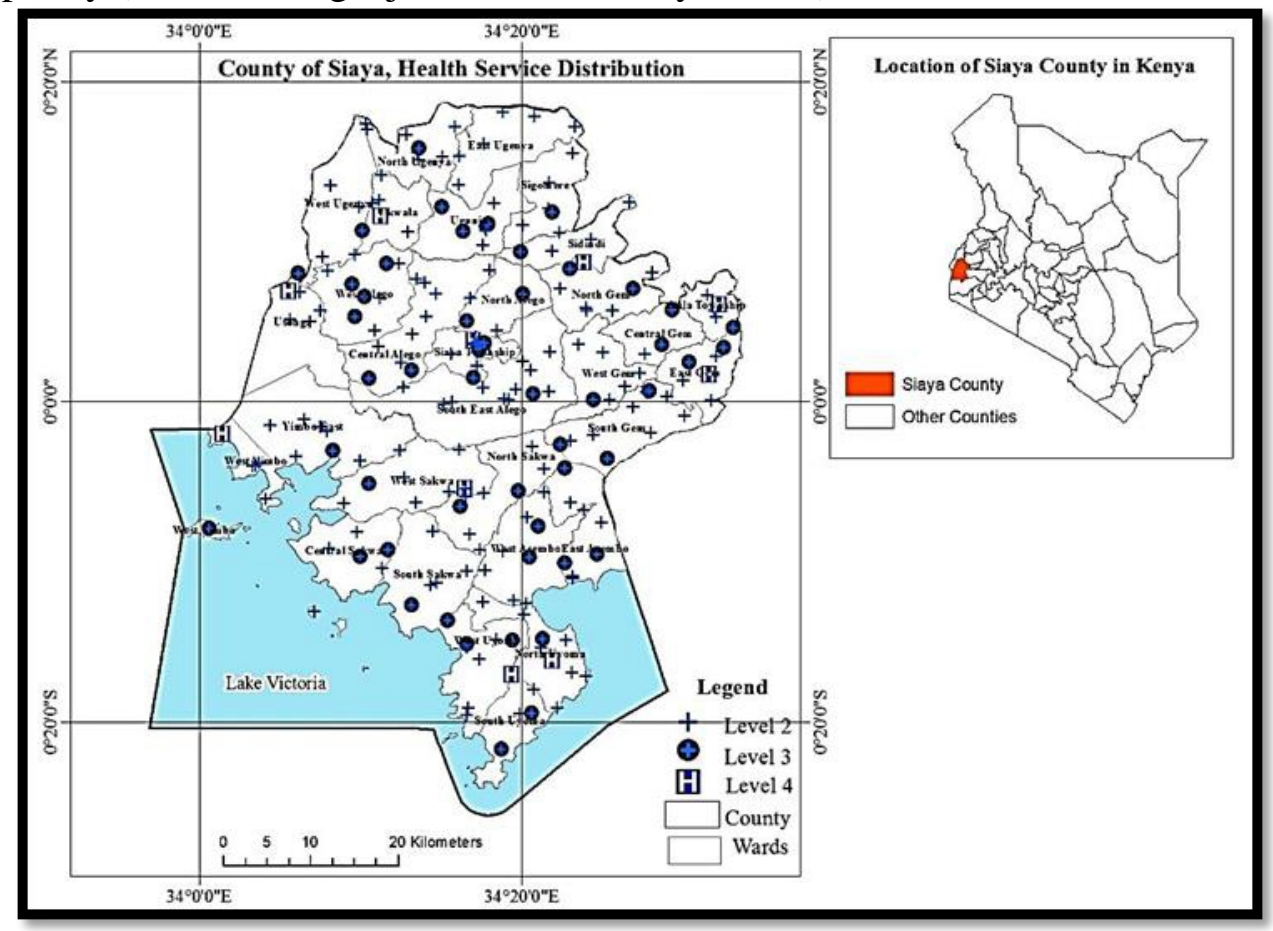

Figure 1: Location and distribution of health facilities in Siaya County, in Kenya

\section{Study population and Sample}

The population comprised 185,922 expected births/pregnancies between June 2013 and June 2017 in Siaya County. All maternal cases which were recorded in the 220 registered health facilities in the County within the same period were sampled. The sample comprised all Skilled Birth Attendance (SBA) cases $(112,436)$ and At least one Antenatal care (ANC1) visit cases $(135,864)$. The target population was projected from population data, as expected births or pregnancies comprised 0.04 of the total population annually (Republic of Kenya, 2014b). Population of the County for August 2009 had to be downscaled backwards to 839,947 in June 2009 through geometric progression, to coincide with health service annual survey for 
patient data in District Health Information System (DHIS 2) which is done by financial years.

\section{Data Collection and Pre-Processing}

SBA and ANC1 annual statistical data was downloaded from Kenyan DHIS 2 with the help of County Health Information Officer. DHIS2 is a webbased, free and open source health management data platform that aggregate statistical data collection, validation, analysis, management, and presentation (Gathua, 2016; MoH, 2016). Geolocation of health facilities and related attributes were downloaded from Kenya Master Health Facility List (KMHFL). KMHFL is a web application with an application with all health facilities and community units in Kenya, whereby each health facility and community unit is identified with unique code, geographical location, administrative location, ownership, type and the services offered. The study was focused on patient-based survey by each registered health facility that was aggregated into Ward Based Maternal Health Service Utilization Database (WMHSUDB) for descriptive and geospatial analysis. WMHSUDB was a shapefile (.shp) format that comprised ward boundary, as spatial data; and LUR of SBA and ANC1 before and after devolution as attribute data. Data for 2012/13 financial year was treated as the year "before devolution", which was basically the onset of devolution. The mean of subsequent four financial years was treated as years "after devolution".

\section{Statistical analysis}

This entailed exploratory spatio-temporal analysis that began with a general trend analysis, basically a graphical line graph showing the maternal health service (SBA, ANC1 and ANC4) utilization ratio at county level through successive five years from commencement of devolution. It was meant to provide a general idea on changes, trends and possible relationships in maternal healthcare utilization after devolution at County Level. A descriptive maps anchored spatial disparities by Wards, before and after devolution. The maps were conceptualized to visually show patterns on whether or not spatial equity or inequities exist and where they existed in the two timed epochs. Spatial equity was deemed to exist when LUR was at least 0.90 (Global standard) or above county mean (local standards) or else spatial inequities suffered.

In order to explore, model and test possible relationships of spatial disparities in maternal health before and after devolution, spatial regression via Ordinary Least Square (OLS) was undertaken using ArcGIS 103. OLS was meant to determine the strength and direction of correlation before and after devolution, magnitude and non-stationarity of changes across Wards, in addition to modelling bivariate relationship in the simple regression line form: 


$$
y=\beta 0+\beta x+\varepsilon
$$

Where $\mathrm{y}$ is the maternal health service LUR after devolution (dependent variable), $\mathrm{x}$ is the maternal health service LUR before devolution (independent variable), $\beta 0$ is intercept, $\beta$ is the coefficient of independent variable, and $\varepsilon$ is the standard error.

The coefficient is very important indicator of magnitude of change on dependent variable by a unit change in independent variable in aggregate. It corroborates trends analysis on changes in maternal utilization at County level after devolution. It also indicates strength, direction and type of relationships. Probability (P value) or (Robust_Pr) shows whether or not of the coefficient is significant in OLS model. The latter is when Koenker (BP) Statistic is significant. Whereas significant coefficient represents the strength and type of relationship between each explanatory variable and the dependent variable, significant Koenker (BP) Statistic indicate that the relationships modeled are not consistent due to non-stationarity (existence of local disparities) or heteroscedasticity within geographical space or data space respectively. Nonstationarity or existence of spatial disparity is ascertained only when a confirmatory Global Moran's I test shows that OLS residuals are spatially random or non-clustered and thus no misspecification. Spatially autocorrelated residuals are beyond OLS to model, thus calls for other robust models, where GWR commonly apply (Wang, Jin, Yan, Alayi, \& Cao, 2016). Koenker (BP) Statistic test was therefore used to confirm existence of spatial disparities in maternal utilization as indicated in descriptive map and GIS database after devolution.

Similarly, Multiple R Squared $\left(\mathrm{R}^{2}\right)$, Adjusted R-Squared and Akaike's Information Criterion (AICc) measured model fit/performance. Adjusted RSquared measured by what percentage did the OLS model predicted the observed dependent variable. The Joint F-Statistic and Joint Wald Statistic were used to measure the overall OLS model statistical significance. It is worth noting that the Joint F-Statistic is trustworthy only when the Koenker (BP) Statistic is not statistically significant $(\mathrm{P}>0.05)$. Otherwise, it should apply Joint Wald Statistic to determine overall model significance. Thus, when Koenker (BP) Statistic is not statistically significant $(\mathrm{P}>0.05)$, the OLS model will become useless and it suggests to use other model for presenting the nonlinear relationships, such as GWR model (ESRI, 2015). A significant Jarque-Bera Statistic $(\mathrm{p}<0.01)$ indicates that the residuals are not normally distributed, thus model predictions are biased (the residuals are not normally distributed). A significant Jarque-Bera Statistic was used to test nonuniformity of changes after devolution, signifying likely persistence of local spatial disparities or spatial heterogeneity. 
The exploratory visual changes, trends and patterns from line graph and descriptive map were subjected to confirmatory tests via OLS to confirm spatial disparities in devolved maternal healthcare utilization existence, relationship and persistence using significant Koenker (BP) Statistic, coefficient of regression, and Jarque-Bera Statistic in OLS spatial regression model. This was in addition to spatial autocorrelation test via Global Moran's I to reaffirm non-stationarity (spatial heterogeneity) and absence of misspecification at County Level (Lin \& Wen, 2011; Wang, et.al., 2016).

\section{Findings:}

\section{Trends and Changes in Local Maternal Utilization at County Level}

The trends in maternal health service local utilization in County of Siaya are described in Figure 2. Expected births generally increased with increase in population and had to be factored by using local utilization ratio (LUR). All expected maternal health needs were not met within Siaya County throughout the study period, as patients were free to choose providers within or without or decline the services altogether. It was observed that SBA uptake was generally increasing but ANC1 uptake was generally decreasing after devolution. While the expected births (demand) increased from 35,941 in $2012 / 13$ to $38,441(7 \%)$ in $2016 / 17$, local utilization of SBA increased from 20001 to 23,127 (15\%), ANC1 decreased from 29,788 to $24,839(-17 \%)$. Similarly, LUR of SBA increased from $0.56(56 \%)$ to average of $0.62(62 \%)$, but LUR of ANC1 declined from 0.83 (83\% to average of $0.71(71 \%)$ after devolution.

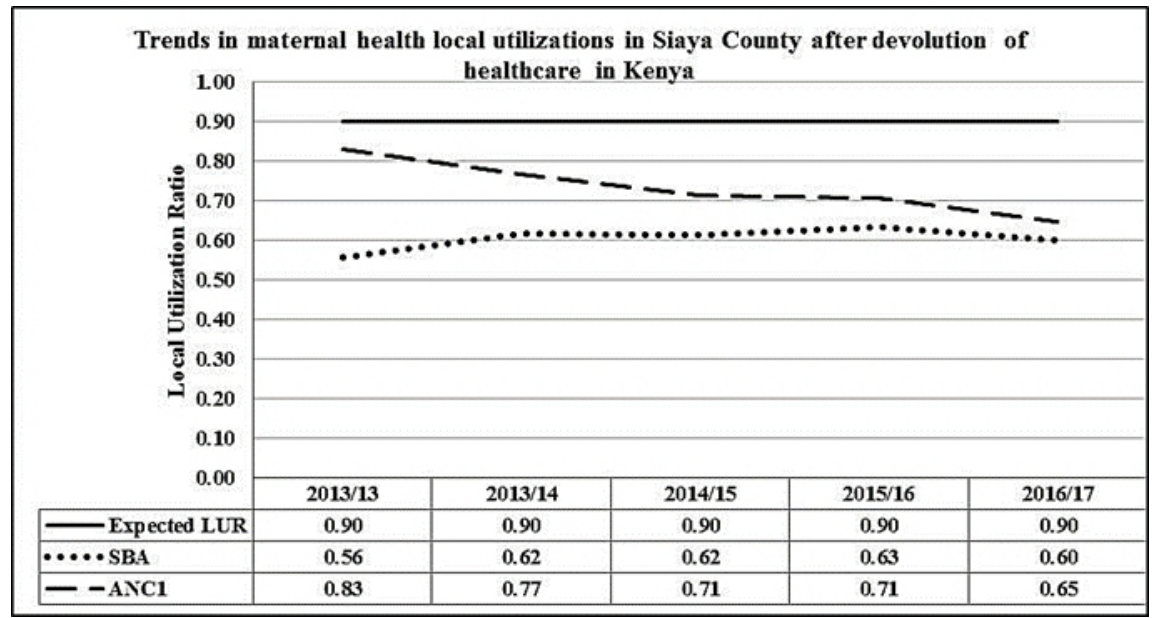

Figure 2: Trends in Maternal Health Local Utilization in Siaya County after Devolution

\section{Exploring Spatial Disparities in SBA Local Utilization by Wards}

The null hypothesis was that there was no change, relationship and spatial disparity and if there were, there was uniform change across all Wards 
in maternal services LUR. Change and spatial disparities in SBA LUR after devolution have been found to exist as per figure 2 and figure 3 respectively, but their significance requires confirmatory tests. The descriptive maps, in figure 3, showed spatial disparities in SBA utilization existed before devolution and persisted afterwards. Only 11 Wards compared to 12 Wards met (global and local) spatial equity after devolution, a marginal reduction by 1. This means 19 (63\%) of the Wards suffer spatial inequities in Local SBA Utilization after devolution compared to 18 (60\%) before devolution.

Results from Ordinary Least Square (OLS) global spatial regression model, using ArcGIS 10.3, returned a significant positive spatial relationship between SBA LUR before and after devolution. This arose from regression coefficient of 1.31, with Robust Probability (Robust_Pr $<0.01$ ), since Koenker (BP) Statistic is also significant, $\mathrm{P}<0.01$ (Table 1). Thus the null hypothesis that there was lack of relationship or no change after devolution was rejected. For every unit change before devolution, there are 1.31 changes after devolution, indicating improvement in SBA local uptake after devolution Countywide. There exists simple linear regressions relationship given by the OLS global regression model, as per table 1:

$$
\mathrm{y}=-0.117+1.31 \mathrm{x}+0.06
$$

Where $\mathrm{y}$ is SBA LUR after devolution and $\mathrm{x}$ is SBA before devolution.

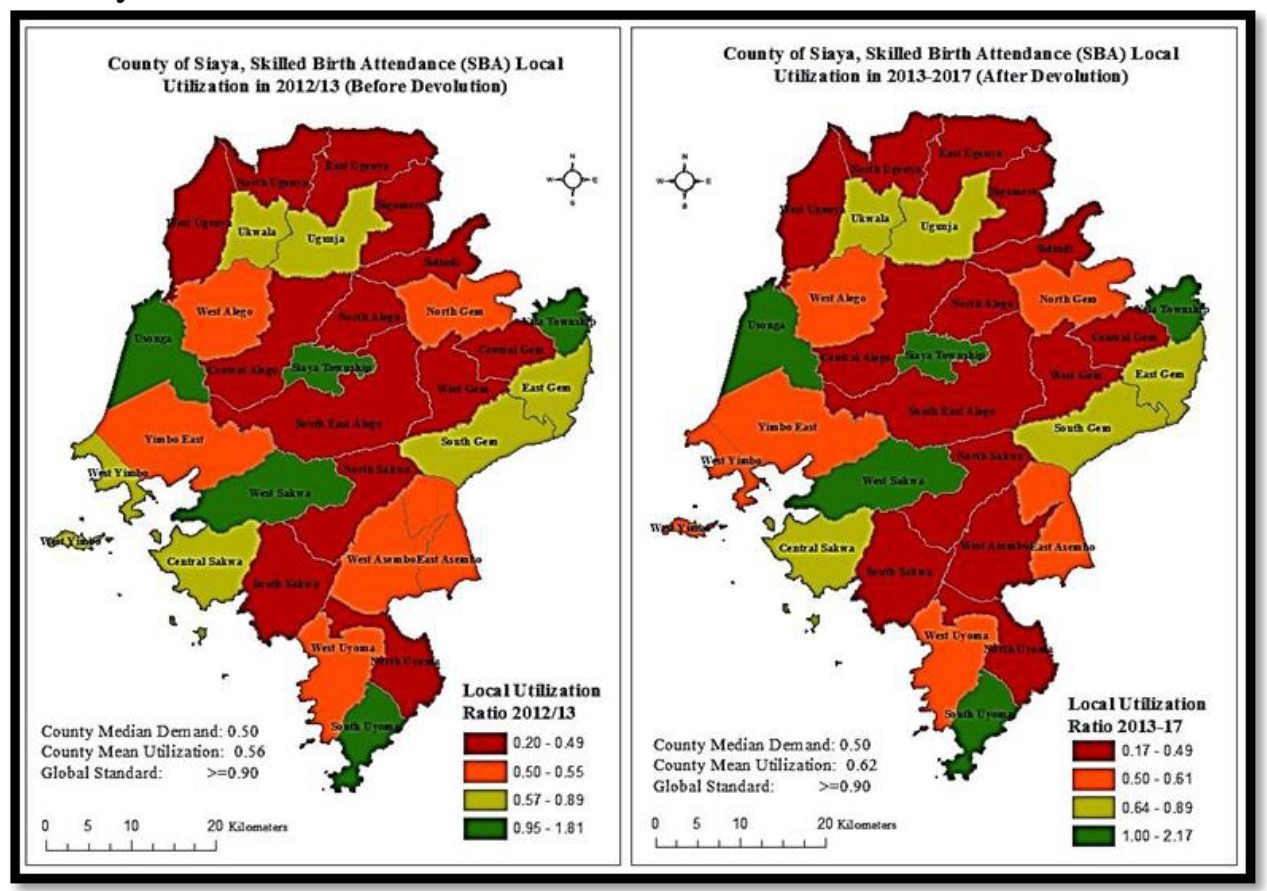

Figure 3: Spatial disparities in Skilled Birth Attendance (SBA) utilization before and after devolution by Wards. 
Any Local Utilization Ratio (LUR) >=0.90 (90\%) meets global equity standards; LUR above County Mean Utilization (CMU) meets local spatial equity; LUR > =0.50 < CMU suffers spatial inequity; LUR $<0.50$ suffers acute spatial inequity.

Adjusted R-Squared showed that the OLS model could account for over $92.9 \%$ of the variations in dependent variable (SBA after devolution) with respect to the independent variable (SBA before devolution). This implies that the totality of spatial processes (healthcare interventions at varied localities) within the County may had led to improved local utilization of maternal services after devolution, but no reduction in spatial disparities or spatial inequities. The County average improved from 0.56 (56\%) to $0.62(62 \%)$ of all SBA demand/needs met at Siaya County, but spatial inequities/disparities increased from $60.0 \%$ to $63.3 \%$ of the Wards.

Table 1: Summary of OLS and Diagnostics Results for SBA_17 \& SBA_13 Variables

\begin{tabular}{|c|c|c|c|c|c|c|c|}
\hline Variable & $\begin{array}{l}\text { Coeff } \\
{[\mathrm{a}]}\end{array}$ & $\begin{array}{l}\text { Std } \\
\text { Erro }\end{array}$ & t-Stat & $\begin{array}{l}\text { Probability } \\
\text { [b] }\end{array}$ & $\begin{array}{l}\text { Robust_ } \\
\text { SE }\end{array}$ & Robust_t & $\begin{array}{l}\text { Robust_Pr } \\
\text { [b] }\end{array}$ \\
\hline Intercept & -0.117 & 0.04 & -2.586 & $0.015^{*}$ & 0.047 & -2.495 & $0.019 *$ \\
\hline SBA_13 & 1.309 & 0.06 & 19.519 & $0.000^{*}$ & 0.107 & 12.204 & $0.000 *$ \\
\hline \multicolumn{8}{|c|}{ Diagnostics of the OLS results } \\
\hline \multicolumn{5}{|c|}{ Input Features: SBA_ANC1_ANC4_Spatial_R } & \multicolumn{3}{|c|}{ Dependent Variable: SBA_17 } \\
\hline \multicolumn{2}{|c|}{ Number of Obs: } & 30 & \multicolumn{4}{|c|}{ Akaike's Information Criterion (AICc)[d]: } & -32.910 \\
\hline \multicolumn{2}{|c|}{ Multiple R-Squared } & 0.932 & \multicolumn{4}{|c|}{ Adjusted R-Squared [d]: } & 0.929 \\
\hline \multicolumn{2}{|c|}{ Joint F-Statistic [e]: } & 380.9 & \multicolumn{4}{|c|}{$\operatorname{Prob}(>\mathrm{F}),(1,28)$ degrees of freedom: } & $0.000 *$ \\
\hline \multicolumn{2}{|c|}{ Joint Wald Statistic } & 148.9 & \multicolumn{4}{|c|}{ Prob(>chi-squared), (1) degrees of freedom: } & $0.000 *$ \\
\hline \multicolumn{2}{|c|}{ Koenker (BP) Stat: } & 7.642 & \multicolumn{4}{|c|}{ Prob(>chi-squared), (1) degrees of freedom: } & $0.006^{*}$ \\
\hline \multicolumn{2}{|c|}{ Jarque-Bera Statistic } & 31.18 & \multicolumn{4}{|c|}{ Prob(>chi-squared), (2) degrees of freedom: } & $0.000 *$ \\
\hline
\end{tabular}

The OLS diagnostics results confirmed existence of non-stationarity or spatial disparity at global scale (county level). This is because Koenker (BP) statistic was statistically significant, $\mathrm{P}<0.01$, and Global Moran's I test of OLS residuals returned non-clustering or lack of spatial autocorrelation $(p=0.87$ and $\mathrm{Z}$ score $=0.17$ ). Thus the null hypothesis that there were no spatial disparities or non-stationarity was rejected. Existence of spatial disparities in SBA utilizations by Wards after devolution and absence of misspecification were confirmed. Significant Jarque-Bera Statistic, $\mathrm{P}<0.01$, indicated that the OLS model predictions were biased since the residuals were not normally distributed. This implies non-uniformity of the changes or residuals along regression line thus indicating persistence of the spatial disparities after devolutions. 


\section{Exploring Spatial Disparities of ANC1 Local Utilization by Wards}

Similarly ANC1 LUR was confirmed to have spatial disparities before and after devolution, while changes after devolution were all negative and non-uniform. Results from OLS spatial regression model, using ArcGIS 10.3, returned a significant positive spatial relationship between ANC1 LUR before and after devolution. This arose from regression coefficient of 0.88 , with Robust Probability (Robust_Pr $<0.01$ ), since Koenker (BP) Statistic was also significant, $\mathrm{P}<0.01$ (Table 2). The model accounts for over $90.8 \%$ of the relationship $(\mathrm{R} 2=0.908)$. Thus the null hypothesis that there was lack of relationship or no change after devolution was rejected, since every one unit change in ANC1 LUR before devolution results into 0.88 units after devolution at County Level. This explains decline of ANC1 LUR from 0.83 before devolution to an average of 0.71 after devolution. Simple linear regression relationships was found to exist in ANC1 LUR before and after devolution (as per table 2), derived OLS global regression model:

$$
\mathrm{y}=-0.022+0.881 \mathrm{x}+0.052
$$

Where $\mathrm{y}$ is ANC1 LUR after devolution and $\mathrm{x}$ is ANC1 before devolution.

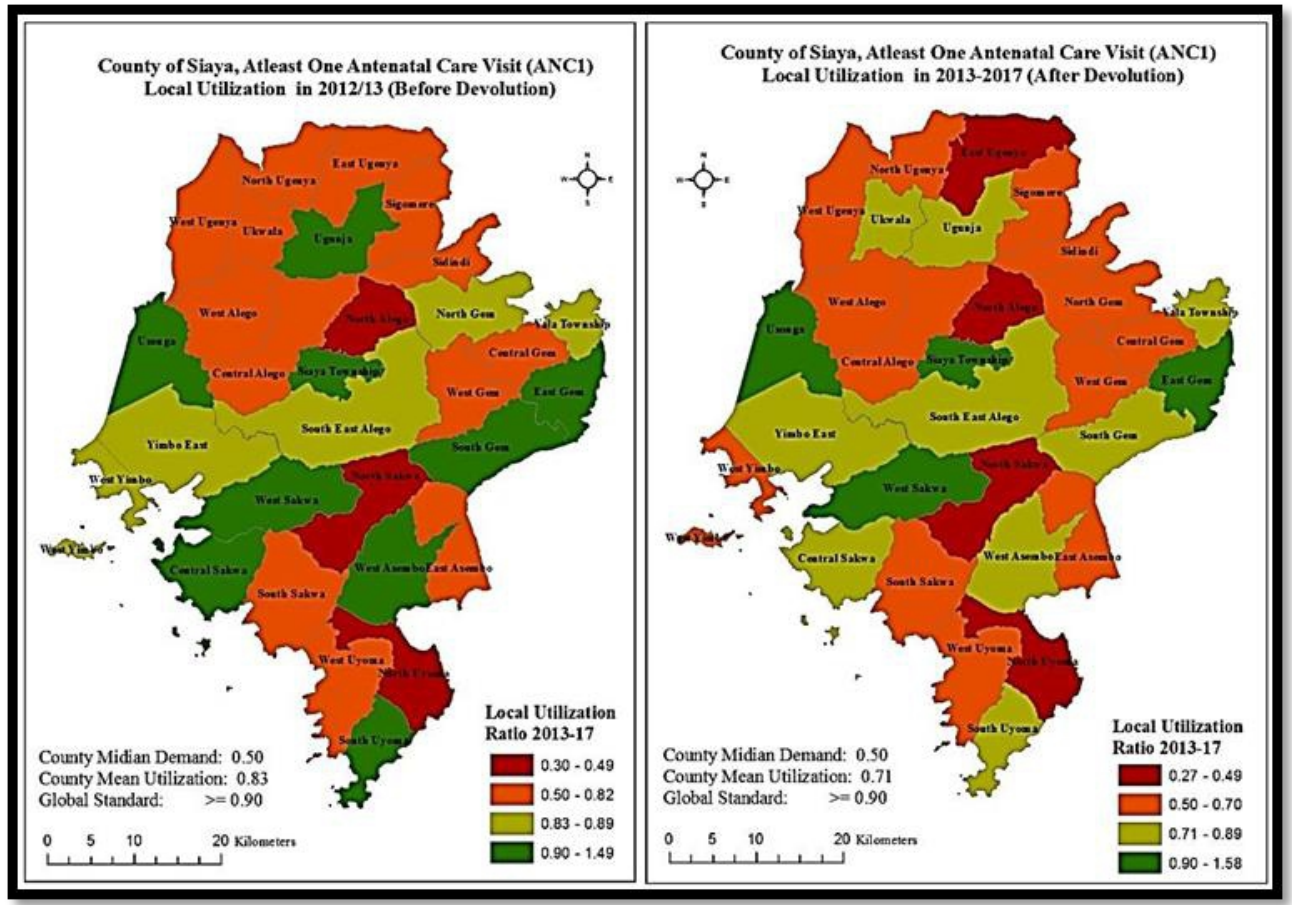

Figure 4: Spatial disparities in At least One Antenatal care Visit (ANC1) before and after devolution in Siaya County. 
Any Local Utilization Ratio (LUR) >=0.90 (90\%) meets global standards; LUR above County Mean Utilization (CMU) meets local spatial equity; LUR >=0.50 < CMU (2012/13) suffers spatial inequity; LUR <0.50 suffers acute spatial inequity.

Ward meeting global standard in spatial equity drastically reduced from nine to four (a reduction of $61.7 \%$ ), while those meeting local equity standards increased from five to nine (increase of $80.0 \%$ ). Ugunja, South Uyoma, West Asembo, Central Sakwa, and South Gem Wards declined from global standards to local standards, implying deterioration in spatial equity. However those suffering spatial inequities increased by only one. Analysis of ANC1 LUR show deteriorating spatial inequities and declining local utilizations after devolution, with significant non-stationarity or spatial disparities (Koenker (BP) Statistic, $\mathrm{p}<0.01$ ). Therefore test for spatial autocorrelation returned non clustering of values $(\mathrm{Z}$ score $=-0.14, \mathrm{P}=0.88)$, confirming existence of spatial disparity of ANC1 LUR by Wards after devolution and absence of misspecifications of explanatory variables (ESRI, 2015). Statistically, the OLS model result indicates best fit and strong relationship. The results confirms that ANC1 needs met locally before and after devolution are significantly positively correlated but declined. It also confirms that the rate of changes in spatial disparities is significantly different, as non-stationarity was unravelled in the OLS Diagnostics (Table 2).

Table 2: Summary of OLS and Diagnostics Results for ANC1_17 \& ANC1_13 Variables

\begin{tabular}{|c|c|c|c|c|c|c|c|}
\hline Variable & $\begin{array}{l}\text { Coeff } \\
\text { [a] }\end{array}$ & $\begin{array}{l}\text { Std } \\
\text { Error }\end{array}$ & t-Stat & $\begin{array}{l}\text { Probability } \\
\text { [b] }\end{array}$ & $\begin{array}{l}\text { Robust_ } \\
\text { SE }\end{array}$ & Robust_t & $\begin{array}{l}\text { Robust_Pr } \\
\text { [b] }\end{array}$ \\
\hline Intercept & -0.022 & 0.046 & -0.478 & 0.636 & 0.060 & -0.370 & 0.714 \\
\hline ANC1_1 & 0.881 & 0.052 & 19.967 & $0.000 *$ & 0.083 & 10.650 & $0.000 *$ \\
\hline \multicolumn{8}{|c|}{ OLS Diagnostics } \\
\hline \multicolumn{5}{|c|}{ Input Features: SBA_ANC1_ANC4_Spatial_R } & \multicolumn{3}{|c|}{ Dependent Variable: ANC1_17 } \\
\hline \multicolumn{2}{|c|}{ Number of Obs: } & \multicolumn{2}{|l|}{30} & \multicolumn{3}{|c|}{ Akaike's Information Criterion (AICc)[d]: } & -58.929 \\
\hline \multicolumn{2}{|c|}{ Multiple R-Squared } & \multicolumn{2}{|c|}{0.911} & \multicolumn{3}{|c|}{ Adjusted R-Squared [d]: } & 0.908 \\
\hline \multicolumn{2}{|c|}{ Joint F-Statistic [e]: } & \multicolumn{2}{|c|}{287.868} & \multicolumn{3}{|c|}{$\operatorname{Prob}(>F),(1,28)$ degrees of freedom: } & $0.000 *$ \\
\hline \multicolumn{2}{|c|}{ Joint Wald Statistic } & \multicolumn{2}{|c|}{113.424} & \multicolumn{3}{|c|}{ Prob(>chi-squared), (1) degrees of freedom: } & $0.000 *$ \\
\hline \multirow{2}{*}{\multicolumn{2}{|c|}{ Koenker (BP) Statistic }} & \multicolumn{2}{|c|}{6.065} & \multicolumn{3}{|c|}{ Prob(>chi-squared), (1) degrees of freedom: } & $0.014 *$ \\
\hline & & \multicolumn{2}{|c|}{2.317} & \multicolumn{3}{|c|}{ Prob(>chi-squared), (2) degrees of freedom: } & $0.000 *$ \\
\hline
\end{tabular}

*Significant

\section{Discussions of Result}

The changes or increasing trends in local SBA uptake at county level, from $56 \%$ to average of $62 \%$ after devolution of healthcare, apparently, did not arise out of devolved healthcare interventions but free maternal policy that 
was operationalized from Mid 2013. This urpsurge in uptake happened within one year, before Counties governance was entrenched in 2014, but stagnated thereafter at between $60 \%$ and $63 \%$ (Figure 2). However, even with improved affordability, the local uptake (SBA LUR) changes by Wards were nonuniform and higher in Wards hosting refferral health facilities implying likely persisence of spatial disparities, especially owing significant positive spatial relationship in SBA local uptake before and after devolutions. This observation is confirmed by result of a study from 77 health facilities that showed statistically significant increase, by $29.5 \%$, in the number of facilitybased deliveries owing to free maternity (Gitobu, Gichangi, \& Mwanda, 2018). It also mimics increases of $26.8 \%$ and $16.2 \%$ in public county referral deliveries and antenatal care attributable to free maternity in Kenya but reduction by $11.9 \%$ and $5.4 \%$ respectively in low cost private hospitals (Njuguna, Kamau, \& Muruka, 2017).

The decline from $83 \%$ to average of $71 \%$ in ANC1 local uptake after devolution may be associated with deterioration in spatial disparities in LUR by Ward. Wards that met global standards reduced by $61.7 \%$, as patient health seeking pattern seem to prefer Wards with referral facilities. The significant spatial relationship between local maternal utilization before and after devolution, with either stagnating or deteriorating disparities or spatial inequities in local uptake, indicate that improvements and/ or utilization are concentrated in certain localities (Wards) but worsening in others.

This finding reaffirms result of a perspective survey showing possible impact of devolved health care in Kenya as increasing uptake of maternal service at referral service, which besides devolution was attributed also to improving transport and free maternity programme (Kilonzo, Kamaara, \& Magak, 2017). It shows that quality overrides distance in health seeking and provider choices. It coincides with nationwide observation that the two most significant barriers to entry in the Kenyan health system are the cost of care, and the availability of suitable care within a reasonable distance (Turin, 2010). Similarly, a study in Pakistan concluded that while physical proximity is important, belief in the efficiency of the healthcare is also a core driver for patient provider choices (Shaikh \& Hatcher, 2004). The increasing and persistent disparities and preference for referral facilities were possibly due to more attention given to secondary facilities or neglect of primary facilities which are more spread out. By passing of proximate facilities for far off secondary facilities for services shows either deficiencies or lack of confidence by targeted users in primary facilities. This certainly can be indictment of devolved healthcare where patients should obtained services "close by".

The devolved healthcare, as exemplified by Siaya County, is apparently not showing signs of addressing spatial disparities from users' 
spatial health seeking habit. May be it is still early or research hasn't been done to inform and evaluate the policy and invoke remedial measures. This mirrors Philippines experience where the first five years of devolved healthcare faced unintended bottlenecks and impacts which had to be addressed (Grundy, et.al., 2003). It is highly likely that political resource allocations in county planning and budgeting have high affinity/priority for bigger projects that happens to be equipping and refurbishing secondary health facilities at expense of primary health facilities which are more spread out. This confirms assertion on preference of mega projects by politicians and policy makers to support their political cause (Flyvbjerg, 2014). This could indeed be one of the unintended consequences of devolution in theory and practice, as it is meant to address regional and local inequities in development (The World Bank, 2005). It re-emphasises perspective that devolved healthcare ought to be matched by comprehensive and quality of primary essential health services, rather than quantity, for effective devolved healthcare in Kenya (Okech \& Lelengwe, 2015).

Patient perspective was so crusial for the study, as it is rarely done by policy makers. Shaikh and Hatcher (2005) reiterated that if health service system is to work, it must start from what users need, such that appropriate policies should be redesigned to address patient needs. User needs or choices is obtainable from their health seeking behaviour, which is hailed as part of wide concept health behaviour, and is of greater interest in planning or evaluating health programmes (WHO, 1995). Patient choice has become the standard practice in healthcare provisions albeit criticisms (Ewert, 2013). Kenya is a good canditate for such as approach, as patients have freedom of choice of health provider and not bound to use proximate services as first point of entry to health delivery system. To get patient perspective, patient-based surveys was applied due to advantages it has over population based surveys. Electronic Health Records, like Kenyans DHIS 2, have been found valuable tools for healthcare reforms (Francois \& Obisike, 2016).

\section{Conclusions and Recommendations}

The paper aimed at exploring spatial disparities in maternal healthcare utilization and establishes prospects of spatial equity in primary healthcare after devolution. The findings show significant spatial relationships in local disparities in maternal health utilization before and after devolution in Siaya County. It also unravelled not only existence of spatial disparities and persistent spatial inequities, but also non-uniform changes at ward level after devolution. With significant spatial relationships and non-uniformity of changes (non-stationarity), spatial disparities and inequities in maternal healthcare is likely to persist, stagnate or deteriorate. Thus, prospects of devolution in reducing local spatial inequities in maternal healthcare 
utilization are low without interventions. This is because even improvement in facility deliveries is attributable to free maternity policy leading to upsurge in public referral services rather than primary healthcare facilities, which are more spread out. Long walk, or travel, to maternal healthcare, particularly SBA, is likely to persist.

Reverting attention to primary health services and facilities, which have higher geographical spread for proximate, quality and comprehensive services that inspire confidence and attraction to targeted users has been recommended. Model health centres should be established in Wards not hosting hospitals as a matter of urgency. The model health centres location should consider centrality. Effective referral system should be established, whereby users are inspired or encouraged to go to nearby facilities as first point of entry, from where they are facilitated to referral facilities where necessary via free ambulance services. Maternity services also need to be widely decentralized. After these priority/urgent interventions, the County should ensure each level of public health facility meets standards in terms of service availability/readiness, infrastructure, human resources, equipment and facilities.

\section{Abbreviations}

ANC1: $\quad$ At least one Antenatal Care visit

ANC4: $\quad$ At least four Antenatal Care visits

GIS: Geographic Information Systems

GWR: Geographically Weighted Regression

LU: $\quad$ Local utilization

LUR: $\quad$ Local utilization Ratio

OLS: Ordinary Least square

SBA: $\quad$ Skilled birth Attendance

\section{Acknowledgement}

I wish to acknowledge County of Siaya for supporting the research with data and valuable information. I wish to also acknowledge National Commission of Science, Technology and Innovation (NACOSTI) for permitting my PhD research from which this article has been drawn. Lastly, I wish to acknowledge Jaramogi Oginga Odinga University of Science and Technology (JOOUST) for admitting me into their $\mathrm{PhD}$ in planning programme and approving the research. And also salute my supervisors for guiding the research and co-producing this paper. $\mathrm{My} \mathrm{PhD}$ thesis is entitled: Planning for Spatial Equity in Devolved Healthcare: A Geospatial Analysis of Land Use - Transport Linkage. 


\section{Funding}

The study had no external funding.

\section{Competing interests}

The authors have no competing interests.

\section{References:}

1. Amer, S. (2007). Towards Spatial Justice in Urban Health Services Planning: A spatial-analytic GIS-based approach using Dar es Salaam-Tanzania as a case study. $\mathrm{PhD}$ Thesis, Enschede, The Netherlands: International Institute for Geo-Information Science and Earth Observatory.

2. Boah, M., Mahama, A. B., \& Ayamga, E. A. (2018, July 17). They receive antenatal care in health facilities, yet do not deliver there: predictors of health facility delivery by women in rural Ghana. BMC Pregnancy and Childbirth, 18(125).

3. Creswell, J. W. (2013). Qualitative inquiry and research design: Choosing among five approaches (3rd ed.). Thousand Oaks, CA: Sage.

4. ESRI. (2015). Interpreting OLS results. (ESRI) Retrieved July 25, 2018 , from http://resources.arcgis.com/en/help/main/10.1/005p/005p0000003000 0000.htm

5. Flyvbjerg, B. (2014). What You Should Know About Megaprojects and Why: An Overview. Project Management Journal.

6. Francois, M. J., \& Obisike, E. E. (2016, May). Accelerating the National Implementation of Electronic Health Records in Canada. European Scientific Journal, 12(15), 65-80.

7. Gathua, P. W. (2016). Assessment of Data Use of the District Health Information System (DHIS 2): A Case Study of Nairobi County. Nairobi: MA Project, University of Nairobi.

8. Gitobu, C. M., Gichangi, P. B., \& Mwanda, W. O. (2018). The effect of Kenya's free maternal health care policy on the utilization of health facility delivery services and maternal and neonatal mortality in public health facilities. 18 (77). BMC Pregnancy and Childbirth, 18(77). doi:10.1186/s12884-018-1708-2

9. Goldberg, J., Hayes, W., \& Huntley, J. (2004). Understanding Health Disparities. Health Policy Institute of Ohio .

10. Grundy, J., Healy, V., Gorgolon, L., \& Sandig, E. (2003). Overview of Devolution of Health services in Philippines. Rural and Remote Health, 3, 1-10. 
11. Haining, R. P. (1994). Designing spatial data analysis modules for geographical information systems. In A. S. Fotheringham, \& P. Rogerson, Spatial analysis and GIS. (pp. 45-63). London,: Taylor.

12. Harry, J. (2006). Equity in development: Why it is important and how to achieve it. Vols. Working Paper 311, November 2009. London: Overseas Development Institute. Retrieved December 6, 2016, from http://www.odi.org.uk

13. Harvey, D. (1992). Social justice, Postmodernism and the City. International Journal of Urban and Regional Research, 16(4), 588601.

14. Jacobs, B., Ir, P., Bigdeli, M., Annear, P., \& Damme, W. (2011). Addressing access barriers to health services: an analytical framework for selecting appropriate interventions in low-income Asian countries. Health Policy and Planning, 27, 288-300

15. Kanbur, R., \& Zhang, X. (2005). Spatial inequality in education and health care in China. China Economic Review, 16(2), 189-204.

16. Karuri, J., Waiganjo, P., Orwa, D., \& Manya, A. (2014). DHIS2: The Tool to Improve Health Data Demand and Use in Kenya. Journal of Health Informatics in Developing Countries, 8(1). Retrieved from www.jhidc.org

17. Katikireddi, S. V., Smith, K. E., Stuckler, D., \& McKee, M. (2016). Perspectives Devolution of power, revolution in public health. Journal of Public Health, 1-7. doi:10.1093/pubmed/fdw031

18. Kilonzo, S., Kamaara, E., \& Magak, K. (2017, March). Improving Access to Maternal Health Care through Devolution in Western Kenya . IDS Bulletin 'Interrogating Decentralisation in Africa', 48(2), 91108.

19. KPMG International. (2013). Devolution of Healthcare Services in Kenya: Lessons Learnt from Other Countries. Nairobi.

20. Lefebvre, H. (1991). The Production of Space. Blackwell.

21. Lin, C., \& Wen, T. (2011). Using geographically weighted regression (GWR) to explore spatial varying relationships of immature mosquitoes and human densities with the incidence of dengue. Int J Environ Res Public Health, 8(7), 2798-815. doi:10.3390/ijerph8072798

22. Liu, Y., Hsiao, W. C., \& Eggleston, K. (1999). Equity in health and health care: the Chinese experience . Social Science \& Medicine, 49(10), 1349-1356. doi:10.1016/S0277-9536(99)00207-5.

23. MoH. (2016). Kenya Master Health Facility List Kenya Documentation Release 0.1.0a2. Nairobi.

24. Naanyu, V., Baliddawa, J., Koech, B., Karfakis, J., \& Nyagoha, N. (2018). Childbirth is not a Sickness; A Woman Should Struggle to 
Give Birth": Exploring Continuing Popularity of Home Births in Western Kenya. Afr J Reprod Health, 22(1), 85-93.

25. Njuguna, J., Kamau, N., \& Muruka, C. (2017). Impact of free delivery policy on utilization of maternal health services in county referral hospitals in Kenya. BMC Health Services Research, 77(429). doi:10.1186/s12913-017-2376-z

26. Okech, T. C., \& Lelengwe, S. L. (2015). Analysis of Universal Health Coverage and Equity on Health Care in Kenya. Global Journal of Health Science, 8(7), 218-227. doi:10.5539/gjhs.v8n7p218

27. Rawls, J. (2001). Justice as Fairness: A Restatement (2nd ed.). Cambridge, Mass: Belknap Press of Harvard University Press.

28. Republic of Kenya. (2010). Constitution of Kenya 2010 [Electronic Version]. Nairobi, Kenya: National Council for Law Reporting. Retrieved November 17, 2016, from http://www.kenyalaw.org/lex/actview.xql?actid=Const2010

29. Republic of Kenya. (2012). County Government Act, No 17 of 2012. Nairobi: Kenya Law Reform Commission.

30. Republic of Kenya. (2014a). Kenya Health Policy 2014-2030: Towards attaining highest standards of health. Nairobi: Ministry of Health.

31. Republic of Kenya. (2014b). Kenya Demographic and Health Survey 2014. Nairobi, Kenya: Kenya National Bureau of Statistics.

32. Shaikh, B. T., \& Hatcher, J. (2004). Health Seeking Behaviour and Health Service Utilization in Pakistan: Challenging the Policy Makers. Journal of Public Health, 27(1), 49-54.

33. Soja, E. W. (2010). Seeking Spatial Justice. Minneapolis: University of Minnesota Press.

34. Starfield, B. (2011). The hidden inequity in health care. International Journal for Equity in Health, 10-15.

35. STC. (2018, August 11). STC 2018 Health Index. Retrieved on August 6, 2018, from http://globalresidenceindex.com/hnwi-index/healthindex./

36. Talen, E., \& Anselin, L. (1998). Assessing Spatial Equity: An Evaluation of Measures of Accessibility to Public Playgrounds. Environmental and Planning A, 30, 595-613.

37. The World Bank. (2005). Equity and Development: World Development Report 2006. Washington DC: The World Bank and Oxford University Press. doi: 10.1596/978-0-8213-6249-5

38. Turin, D. R. (2010). Health Care Utilization in the Kenyan Health System: Challenges and Opportunities. . Student Pulse, 2(9). Retrieved February 16, 2017, from http://www.studentpulse.com/a?id=284 
39. UNFPA. (2014). Counties with the Highest Burden of Maternal Mortality. Dispatch, 13 August 2014. Nairobi, Kenya. Retrieved December 6, 2016, from http://kenya.unfpa.org/news/countieshighest-burden-maternal-mortality

40. UNFPA. (2015). Kenya Annual Report. Nairobi, Kenya: UNFPA Kenya Country Office.

41. Venkatapuram, S., Bell, R., \& Marmot, M. (2010). The right to sutures: social epidemiology, human rights, and social justice. Health Hum Rights, 12, 3-6.

42. Wang, H., Xu, T., \& Xu, J. (2007). Factors Contributing to High Costs and Inequality in China's Health Care System. JAMA, 298(16), 19281930. doi:10.1001/jama.298.16.1928. PMID 17954544.

43. Wang, W., Jin, Y.-Y., Yan, C., Alayi, A., \& Cao, M.-Q. (2016). Local spatial variations analysis of smear positive tuberculosis in Xinjiang using Geographically Weighted Regression model. BMC Public Health. doi:DOI 10.1186/s12889-016-3723-4

44. WHO. (2008). Devolved power: key for health care in India. An interview with Michael Tharakan. Bulletin of the World Health Organization, 86(11), 817-908.

45. WHO. (2015). Global Reference List of 100 Core Health Indicators. Geneva: World Health Organization. Retrieved June 25, 2016, from http://apps.who.int/iris/bitstream/10665/173589/1/WHO_HIS_HSI_2 015.3_eng.pdf?ua $=1$

46. Yin, R. (1994). Case study research: Design and methods (2nd ed.). Beverly Hills, CA: Sage Publishing.

47. Zaidah, Z. (2007, June 9). Case study as a research method. Jurnal Kemanusiaan bil., 1-6.

48. Zhao, Z. (2006). Income Inequality, Unequal Health Care Access, and Mortality in China . Population and Development Review, 32(3), 461483. doi: 461-483. doi:10.1111/j.1728-4457.2006.00133.x 